\title{
AKTIVITAS ANTIFUNGI INFUSA UMBI BAWANG PUTIH (Allium sativum Linn), DAUN KUMIS KUCING (Orthosiphon aristatus) DAN KOMBINASI KEDUANYATERHADAP Candida albicans MENGGUNAKAN METODE CAKRAM KERTAS
}

\author{
${ }^{1}$ Poppy Dwi Citra Jaluri, Febry Nur Ngazizah \\ ${ }^{1}$ STIKes Borneo Gendekia Medika Pangkalan Bun \\ Email : Poppyjaluri@gmail.com,Email: febrinurngazizah@gmail.com
}

\begin{abstract}
ABSTRAK
Aktivitas Antifungi Infusa Umbi Bawang Putih (Allium Sativu, Linn), Daun kumis kucing (Orthosiphon Aristatus, Linn) dan kombinasi keduanya terhadap Candida Albicans menggunakan metode cakram kertas.Penelitian ini bertujuan untuk Mengetahui efek yang terjadi jika umbi bawang putih (Allium Sativum Linn) dan daun kumis kucing (Orthosiphon Aristatus) di kombinasikan sebagai antifungi untukCandida albicans. Uji antifungi ini dilakukan dengan mengkombinasikan infusa umbi bawang putih dan daun kumis kucing pada konsentrasi 10\%:10\%, 5\%:10\%, 2,5\%:10\%, 1,25\%:10\%, 10\%:1,25\%, 10\%:5\% dan 10\% b/v:2,5\% b/v. Dari hasil penelitian uji antifungi infusa umbi bawang putih, infusa daun kumis kucing dan kombinasi keduanya mampu menghambat pertumbuhan jamur Candida albicans.Berdasarkan hasil penelitian yang telah dilakukan bahwa dari hasil percobaan tunggal untuk umbi bawang putih dan daun kumis kucing yang efektif dalam menghambat jamur candida albicans adalah daun kumis kucing (Orthosiphon Aristatus) dengan konsentrasi $10 \% \mathrm{~b} / \mathrm{v}$ dan diameter hambatnya sebesar $20,25 \mathrm{~mm}$, untuk uji pengamatan visual umbi bawang putih dan daun kumis kucing dalam menghambat jamur candida albicans dari hasil yang didapatkan bahwa pada uji pengamatan visual didapatkan hasil yang bersifat antagonis dari masing-masing konsentrasi dalam menghambat jamur candida albicans.
\end{abstract}

Kata Kunci : Antifungi, bawang putih, daun kumis kucing, Candida albicans, Cakram kertas

\section{ANTIFUNCTIONAL ACTIVITIES OF WHITE INFUSION INFUSION (Allium sativum Linn), CAT LEAVES LEAF (Orthosiphon aristatus) AND COMBINATION OF SECONDARY INTEGRATION OF Candida albicans USING THE PAPER DISCUSSION METHOD}

\begin{abstract}
Antifungal Activity of Garlic Bulbs (Allium Sativu, Linn), Cat Whiskers (Orthosiphon Aristatus, Linn) and the combination of both of them against Candida Albicans using the paper disc method. and the leaves of cat's whiskers (Orthosiphon Aristatus) are combined as an antifungal for Candida albicans. This antifungal test was carried out by combining garlic tuber infusions and cat whiskers leaves at concentrations of 10\%: 10\%, 5\%: 10\%, 2.5\%: 10\%, 1.25\%: 10\%, 10\%: $1.25 \%, 10 \%: 5 \%$ and $10 \% \mathrm{w}$
\end{abstract}


/ v: $2.5 \% \mathrm{w} / \mathrm{v}$. From the results of antifungal test studies of garlic tubers, cat whiskers infusion leaves and a combination of both are able to inhibit the growth of the fungus Candida albicans. is the leaves of cat's whiskers (Orthosiphon Aristatus) with a concentration of $10 \% \mathrm{w} / \mathrm{v}$ and the inhibitory diameter of $20.25 \mathrm{~mm}$, for visual observation test of garlic bulbs and leaves of cat's whiskers in inhibiting the fungus candida albicans from the results obtained that the visual observation test obtained antagonistic results of each concentration in inhibiting the fungus candida albicans.

Keywords: Antifungal, garlic, cat's whiskers, Candida albicans, Paper disc

\section{PENDAHULUAN}

Indonesia adalah negara yang memiliki sumber daya alam yang amat besar. Kekayaan alam ini potensial untuk dimanfaatkan sebagai bahan baku yang bersumber dari alam. Saat ini masyarakat cenderung memilih untuk kembali ke alam. Tanaman yang dapat dijadikan sebagai bahan baku alam salah satunya adalah umbi bawang putih (Allium sativum Linn.) dan daun kumis kucing (Orthosiphon aristatus).

Pengobatan tradisional merupakan salah satu warisan budaya bangsa Indonesia yang perlu digali serta dikembangkan. Berbagai macam penyakit dapat diobati dengan cara memanfaatkan obat tradisional dari tanaman-tanaman tertentu yang mudah serta mudah didapat. Pengobatan dengan menggunakan tanaman obat tradisional tersebut memiliki kelebihan yaitu efek samping yang ditimbulkan relatif lebih kecil.

Bawang putih merupakan sayuran rempah yang meskipun bukan asli Indonesia, namun penggunaannya banyak di Indonesia. Boleh dikata, tiada hari tanpa bawang, tiada masakan tanpa bawang. Penggunaan bawang putih sebagai obat tradisional telah beratus-ratus tahun yang lalu dikenal di berbagai negara di dunia,seperti Romawi, Mesir Kuno, India, Bulgaria dan sebagainya. Infeksi usus, infeksi saluran pernafasan, kulit dan luka-luka akibat gigitan binatang berbisa dapat disembuhkan dengan obat yang ramuannya menggunakan bawang putih.

Menurut hasil penelitian Aras Utami perasan umbi bawang putih $25 \%$ dengan ketokonazol 2\% secara in vitro dapat menghambat pertumbuhan Candida albicanspada kandidiasis vaginalis. Secara deskriptif, perasan umbi bawang putih $25 \%$ memiliki efektifitas yang lebih tinggi dibandingkan dengan ketokonazol 2\% secara in vitro dalam menghambat pertumbuhan Candida albicans pada kandidiasis vaginalis.

Sementara itu kumis kucing (Orthosiphon aristatus) merupakan tanaman obat berupa tumbuhan berbatang basah yang tegak. Tanaman ini dikenal dengan istilah java tea. Orthosiphon aristatus sudah dikenal dalam sistem pengobatan tradisional sebagai obat pelancar air seni. Tanaman ini dapat tumbuh pada berbagai daerah, baik di daerah pegunungan atau dataran rendah dan banyak terdapat sebagai tanaman liar. Tanaman ini telah digunakan secara luas dalam obat-obat tradisional atau fitoterapi dalam bentuk rajangan, serbuk, pil, tablet, kapsul, dan lain-lain.

Daun kumis kucing mengandung minyak atsiri yang dapat menghambat pertumbuhan fungi 
Candida albicans. Pada penelitian Ridawati dkk dengan judul penelitian aktivitas antifungi minyak atsiri jinten putih terhadap Candida parapsilosis SS25, $C$. orthopsilosis NN14, $C$. metapsilosis MP27, dan C. etchellsii MP18 menunjukan bahwa mintak atsiri memiliki potensi antifungi yang kuat dalam menghambat pertumbuhan fungi.

Dalam penelitian ini akan diuji kombinasi antara infusa umbi bawang putih (Allium sativum Linn) dan daun kumis kucing (Orthosiphon aristatus) sebagai antifungi Candida albicans.

Masalah yang dapat diidentifikasi adalah apakah terdapat perbedaan dari kombinasi umbi bawang putih (Allium sativum Linn) dan daun Kumis Kucing (Orthosiphon aristatus) dibandingkan dengan simplisia tunggal sebagai antifungi untuk candida albicans, tujuan penelitian adalah mengetahui efek yang terjadi jika umbi bawang putih (Allium sativum Linn) dan daun kumis kucing (Orthosiphon aristatus) di kombinasikan sebagai antifungi untuk Candida albicans. Diharapkan penelitian ini dapat memberikan gambaran dan informasi mengenai kombinasi infusa umbi bawang putih (Allium sativum Linn) dan daun kumis kucing (Orthosipon aristatus) sebagai antifungi Candida albicans.

\section{Metode Penelitian}

Pada penelitian ini dilakukan pengujian antifungi infusa umbi bawang putih (Allium sativum Linn) dan infusa daun kumis kucing (Orthosiphon aristatus) terhadap candida albicans dengan metode difusi agar menggunakan cakram kertas. Tahap penelitian dimulai dengan determinasi tanaman, pengumpulan tanaman, pembuatan infusa, pengujian aktivitas antifungi, pengujian konsentrasi hambat minimum (KHM), kesetaraan terhadap antifungi pembanding. Pengujian aktivitas antifungi dilakukan dengan menggunakan metode difusi agar dengan menggunakan cakram kertas. Daerah hambatan yang terbentuk ditunjukan dengan daerah bening atau zona bening di sekitar cakram kertas yang akan menjadi parameter terhadap potensi kerjanya. Penelitian dilanjutkan dengan menentukan konsentrasi hambat minimum (KHM) infusa umbi bawang putih ( Allium sativum Linn) dan daun kumis kucing (Orthosiphon aristatus). Selanjutnya dilakukan pengujian kesetaraan aktivitas infusa umbi bawang putih (Allium sativum Linn) dan daun kumis kucing (Orthosiphon aristatus) terhadap ketokonazol candida albicans.

\section{HASIL DAN PEMBAHASAN}

Tujuan dari penelitian ini untuk mengetahui efek yang terjadi jika umbi bawang putih (Allium sativum Linn) dan daun kumis kucing (Orthosiphon aristatus) di kombinasikan sebagai antifungi untuk Candida albicans.

Bawang putih merupakan sayuran rempah yang meskipun bukan asli Indonesia, namun penggunaannya sebagai bumbu pelezat masakan sungguh lekat dengan lidah Indonesia. Penggunaan bawang putih sebagai obat tradisional telah beratus-ratus tahun yang lalu dikenal di berbagai negara di dunia, seperti Romawi, Mesir Kuno, India, Bulgaria dan sebagainya. Infeksi usus, infeksi saluran pernafasan, kulit dan luka-luka akibat gigitan binatang berbisa banyak dapat disembuhkan dengan obat yang ramuannya menggunakan bawang putih.

Sementara itu kumis kucing (Orthosiphon aristatus) merupakan 
tanaman obat berupa tumbuhan berbatang basah yang tegak. Tanaman ini dikenal dengan istilah java tea. Orthosiphon aristatus sudah dikenal dalam sistem pengobatan tradisional sebagai obat pelancar air seni. Tanaman ini dapat tumbuh pada berbagai daerah, baik di daerah pegunungan atau dataran rendah dan banyak terdapat sebagai tanaman liar. Tanaman ini telah digunakan secara luas dalam obat-obat tradisional atau fitoterapi dalam bentuk rajangan, serbuk, pil, tablet, kapsul, dan lain-lain.

Pada penelitian ini dilakukan uji aktivitas antijamur Candida albicans infusa daun kumis kucing (Orthosiphon aristatus) dan umbi bawang putih (Allium sativum L). Tanaman yang digunakan pada penelitian ini diambil dari jalan Samarang Garut Jawa barat, untuk memastikan identitas tanaman uji maka dilakukan determinasi. Determinasi dilakukan di Herbarium Bandung Ilmu dan Teknologi Hayati ITB Bandung. Hasil determinasi menunjukan bahwa benar tanaman tersebut adalah daun kumis kucing (Orthosiphon aristatus) dan umbi bawang putih (Allium sativum L), selain itu telah dilakukan penapisan fitokimia bertujuan untuk mengetahui golongan senyawa kimia yang terkandung dalam tanaman uji, daun kumis kucing (Orthosiphon aristatus) terdeteksi adanya flavonoid, saponin, polifenol, steroid, triterpenoid, kuinon, monoterpen dan seskuiterpen (Tabel IV.2). Untuk hasil penapisan fitokimia tanaman uji umbi bawang putih (Allium sativum L) terdeteksi adanya flavonoid, saponin, tanin, dan steroid/triterpenoid (Tabel IV.1).

Hasil uji aktivitas infusa umbi bawang putih (Allium sativum L) dan daun kumis kucing (Orthosiphon aristatus) terhadap Candida albicans menunjukan yang lebih efektif dalam menghambat jamur Candida albicans adalah infusa daun kumis kucing (Orthosiphon Aristatus) dengan konsentrasi $10 \% \mathrm{~b} / \mathrm{v}$ dan diameter hambat nya sebesar 20,25 mm (Tabel IV.4), sedangkan umbi bawang putih pada dosis yang sama yakni $10 \% \mathrm{~b} / \mathrm{v}$ dalam mengambat jamur candida albicans adalah 11,75 mm (Tabel IV.3). Pada uji pengamatan visual pada infusa umbi bawang putih (Allium Sativum L) dan daun kumis kucing (Orthosiphon Aristatus) dengan jarak 1 $\mathrm{cm}$ antara cakram infusa umbi bawang putih (Allium Sativum L) dan cakram infusa daun kumis kucing (Orthosiphon Aristatus), didapatkan hasil yang bersifat antagonis dari masing-masing konsentrasi dalam menghambat jamur Candida albicans (Gambar V. 10) yaitu pada dosis $10 \%$ b/v: $10 \%$ b/v, $5 \%$ b/v: $10 \%$ b/v, 2,5\% b/v: $10 \%$ b/v, 1,25\% b/v:10\% b/v, 10\% $\mathrm{b} / \mathrm{v}: 1,25 \%$ b/v, $10 \%$ b/v:5\% b/v dan $10 \% \mathrm{~b} / \mathrm{v}: 2,5 \% \mathrm{~b} / \mathrm{v}$.

Pada Penentuan Konsentrasi Hambat Minimum (KHM) infusa umbi bawang putih (Allium sativum L) dan daun kumis kucing (Orthosiphon aristatus) terhadap jamur Candida albicans. Diperoleh nilai KHM dari infusa umbi bawang putih dan infusa daun kumis kucing adalah sebesar $0,75 \%$. Adapun kesetaraan terhadap ketokonazol untuk Candida albicans adalah sebesar $9,26 \times 10^{-04}$ (Tabel IV. 7) dan 4,37X10 $0^{-03}$ (Tabel IV. 8).

\section{KESIMPULAN DAN SARAN}

\section{Kesimpulan}

Dari hasil penelitian uji antifungi infusa umbi bawang putih (Allium sativum Linn) dan daun kumis kucing (Orthosiphon aristatus) terhadap Candida albicans dapat disimpulkan bahwa infusa umbi bawang putih 
(Allium sativum Linn)dan daun kumis kucing (Orthosiphon aristatus) mampu menghambat pertumbuhan jamur Candida albicans. Hasil percobaan tunggal untuk umbi bawang putih dan daun kumis kucing yang efektif dalam menghambat jamur candida albicans adalah daun kumis kucing (Orthosiphon aristatus) dengan konsentrasi $10 \% \quad \mathrm{~b} / \mathrm{v}$ dan diameter hambatnya sebesar 20,25 $\mathrm{mm}$; sedangkan untuk uji pengamatan visual umbi bawang putih dan daun kumis kucing dalam menghambat jamur Candida albicans didapatkan hasil yang bersifat antagonis dari masingmasing konsentrasi dalam menghambat jamur Candida albicans. Dari hasil pengujian tersebut dapat disimpulkan bahwa kombinasi antara infusa umbi bawang putih (Allium sativum L) dan daun kumis kucing (Orthosiphon aristatus) menunjukan efek antagonis.

\section{Saran}

Perlu dilakukan penelitian lebih lanjut terhadap senyawa aktif pada umbi bawang bawang putih (Allium sativum L) dan daun kumis kucing (Orthosiphon aristatus) yang berkhasiat sebagai antifungi.

\section{DAFTAR PUSTAKA}

Rukmana, R., 1995, "Budidaya Bawang Putih", Kanisius, Yogyakarta, Hlm. 24-26.

Utami, A., 2006, "Uji Banding Efektifitas Perasan Umbi Bawang Putih dengan Ketokonazol 2\% secara In Vitro terhadap Pertumbuhan Candida Albicans pada Kandidiasis Vaginalis", Universitas Dipononegoro, Semarang, Hlm. 19-20.
Ditjen POM, 1980, "Materia Medika Indonesia", Jilid IV, Departemen Kesehatan RI, Jakarta, Hlm. 55.

Ridawati, Dkk., 2009, "Aktivitas Antifungi Minyak Atsiri Jinten Putih terhadap Candida Parapsilosis SS25, C. Orthopsilosis NN14, C. Metapsilosis MP27, dan C. Etchellsii MP18", Makara sains, vol 15, Hlm. 58-62.

Simatupang, M, M., 2009, "Candida Albicans", $\quad$ Fakultas Kedokteran USU, (Medan), Hlm. 22-23.

Thomas, A.N.S., 1989,“Tanaman Obat Tradisional", Kanisius, Yogyakarta, Hlm. 34.

Made, S., 2009,"Efektifitas Ekstrak Bawang Putih (Allium sativum) dalam Menghambat Pertumbuhan Jamur Legenidium sp", Bukit Jimbaran, Bali, Hlm. 22.

Cronquis, A., 1981, "an Integrated System of Classification of flowering Plants", Colombia University Press, Armero, Hlm. 20.

Harbone, JB., 1987, "Metode Fitokimia: Penuntun Cara Modern Menganalisis Tumbuhan, Ed II'. Penerjemah Padmawinata K dan Soediro J., Niksolihin Editor, ITB, Bandung, Hlm. 34.Anonim, 1993, "Penepisan Farmakologi, Pengujian Fitokimia dan Pengujian Klinik”, Jakarta, Hlm. 59-60. 